\title{
Сюндюкова А.P. \\ Некоторые особенности интегральной индивидуальности человека в связи с различными группами крови
}

Башкирский государственный педагогический университет им. Акмулль (Россия, Уфа)

doi: $10.18411 / \mathrm{j}-05-2021-32$

\section{Аннотация}

Данная статья направлена на изучение особенностей индивидуальности людей с различными группами крови. Была выявлена взаимосвязь между некоторыми особенностями индивидуальности людей и группами крови среди выборки 410 студентов педагогического университета, которые были физически здоровы и чей возраст колеблется в пределах 18-25 лет. Респонденты были распределены между четырьмя группами по группам крови $(\mathrm{A}, \mathrm{B}, \mathrm{AB}, \mathrm{O})$ почти в одинаковом количестве, за исключением группы крови (АВ) из-за ее дефицита среди населения в целом. Исследование показало, что есть достоверность наличия взаимосвязи таких показателей, как уровень самооценки и уровень агрессивности с группами крови.

Ключевые слова: группа крови, индивидуальность, темперамент, уровень агрессивности, уровень самооценки, доминирующий инстинкт.

\section{Abstract}

This article is aimed at studying the personality characteristics of people with different blood groups. The relationship between certain personality traits and blood types was revealed among a sample of 410 students of the Pedagogical University who were physically healthy and whose age ranges from 18 to 25 years. The respondents were divided into four groups by blood group $(\mathrm{A}, \mathrm{B}, \mathrm{AB}, \mathrm{O})$ in almost the same amount, with the exception of blood group $(\mathrm{AB})$ due to its deficiency in the general population. The study showed that there is a significant correlation between indicators such as the level of self-esteem and the level of aggressiveness with blood groups.

Key words: blood type, personality, temperament, level of aggressiveness, level of self-esteem, dominant instinct.

Интерес к изучению групп крови возрос еще в конце прошлого века и начале нынешнего не только с точки зрения научных исследований, но и в связи с ростом народного любопытства. Группы крови считаются одними из наиболее важных признаков, которые различаются с различием народов по всему миру. Считается, что существует наследственная связь между людьми с различными группами крови и их психическим состоянием [1].

Существует убеждение, что каждая группа крови имеет свои специфические характеристики. Например, у людей с II(A) группой крови наблюдается некая предрасположенность к спокойствию во время различных кризисов, но они склонны избегать пика своих эмоций, чувствуют себя некомфортно в незнакомой компании, ищут дружбы, наслаждаются ответственностью и целеустремленностью, стремятся к успеху и совершенству. Представители III(B) группы крови более практичны, чем другие группы. У них есть цели и сила мышления, они больше интересуются своими мыслями и более расслаблены. Представители I(0) группы крови наиболее гибкие люди и проявляют инициативу. Они начинают свои проекты довольно уверенно, но легко сдают свои позиции, сталкиваясь с трудностями, так же ценят мнение других и хотят быть в центре внимания, обладают высокой уверенностью в себе и творческими способностями. Лица с IV(AB) группой крови являются социальными личностями и имеют социальные контакты, доверяют людям, способны легко адаптироваться в социуме [4]. 
Личность-это устойчивая смесь черт, позиций, интересов, поведения, эмоций и других факторов, которые формируются в результате взаимодействия с окружающей средой, в результате чего черты личности влияют на несколько особенностей естественного и больного поведения, в результате чего они связаны с темпераментом и являются самой основной частью личности. Айзенк Г.Ю в своей теории опирался на физиологию и генетику, в силу чего считал, что личностные различия формируются еще на генетическом уровне и наследуются от предков, но он и не упускал тот факт, что приобретенные привычки так же формируют человека, как личность и играют большую роль в его становлении [2]. Ученые пришли к выводу, что некоторые психологические черты и нравственность человека передаются по крови и наследственности. Было указано, что многие люди, имеющие одну и ту же группу крови, сходны в этике и поведении.

Текущее исследование проводилось в соответствии методологией, которая была подобрана согласно целям исследования. Опрос был проведен в Башкирском государственном педагогическом университете им.М. Акмуллы, в котором приняли участие 410 студентов женского пола. Исследование проводилось методом опроса студентов ВУЗа, по специально разработанному опроснику, который включал сведения о возрасте, группе крови по системе АB0, резус фактору, а также вопросники для определения психофизиологических особенностей респондентов. Опросы были направлены на выявление доминирующего инстинкта (по методике В.И.Гарбузова) [1]; изучение типа темперамента (по методике Г.Айзенка) [2]; изучение уровня самооценки (по методике А.Ассингера) [5]; изучение уровня агрессивности проводилось (по опроснику А.Ассингера) [3].

Исследование было направлено на выявление взаимосвязи групп крови и индивидуальностей человека, таких как темперамент, доминирующий инстинкт, уровень агрессивности и уровень самооценки. Люди, обладающие какой-то определённой группой крови, распределены по земному шару неравномерно: где-то преобладает одна группа крови, где-то - другая. Так, выяснилось, что среди объектов нашего исследования преобладают люди со II группой крови - 39,5\% (162 чел.), I группу крови имеют 28,8\% (118 чел.), III - 27,8\% (114 чел.), а «носителем» IV группы крови являются 3,9\% учащихся (116 чел.).

По типу доминирующего инстинкта была выявлена закономерность преобладания альтруизма среди представителей первой и второй группы крови. По процентному соотношению альтруизм среди первой группы составляет 19,5\%, среди второй группы 22,2\%. Самый наименьший процентный показатель имеет инстинкт сохранения достоинства $(7,6 \%)$ у первой группы. Среди всех групп крови наименьший показатель имеет инстинкт доминирования (4,9\%) у носителей второй группы крови. У носителей третей группы крови ярко выражен инстинкт продолжения рода. Для них характерна такая особенность, как чрезмерная любовь к детям, жизнь ради семьи, тенденция к проявлению чрезмерной заботы о своих детях. У четвертой группы сложно выделить только один инстинкт, так как количество респондентов не позволяет детально изучить особенности доминирования инстинкта. В рамках нашего исследования с таким количеством испытуемых можно выделить инстинкт сохранения достоинства.

Таким образом, у носителей первой и второй группы крови преобладает альтруистический инстинкт, носители третей группы крови преимущественно имеют инстинкт продолжения рода, а у четвертой группы крови доминирует инстинкт сохранения достоинства. Наиболее часто встречаются инстинкты: альтруистический, исследовательский, продолжения рода, свободы и сохранения достоинства. В рамках данного исследования достоверность различий по $\mathrm{t}$-критерию Стьюдента с определением уровня значимости $p(p<0,05)$ взаимосвязь доминирующего инстинкта с принадлежностью к группам крови не установлена. 
Изучение типа темперамента по методике Г.Ю. Айзенк показало, что среди носителей первой группы крови большинство составляют холерики - 31,4\%, затем меланхолики $-20,3 \%$, сангвиники $-17,8 \%$, флегматики $-13,6 \%$ и люди со смешанным типом темперамента - $16,9 \%$. У представителей второй группы крови тип темперамента был следующим: холерик - 24,1\%, флегматик - 22,8\%, меланхолик $20,3 \%$, сангвиник - 14,2\%, люди смешанного типа составляют $18,5 \%$. Среди носителей третьей группы крови распределение следующее: флегматики - 22,8\%, холерики и меланхолики - 21,9\%, сангвиники - 18,4\%, смешанный тип - 15,0\%. Среди представителей 4-й группы крови равное распределение в парах наблюдалось у сангвиников и флегматиков - 25,0\%, у холериков и меланхоликов - $18,8 \%$, у смешанного типа - 12,4\%. Таким образом, первая и вторая группа крови определяется большим процентом холериков, которые характеризуются, как люди с высоким уровнем психической активности, энергичные и способные к нервным срывам. Третья группа крови представлена флегматическим темпераментом. Флегматики - это самый уравновешенный тип темперамента, отличающийся спокойствием, инертностью. У носителей четвертой группы крови помимо флегматического темперамента, есть тенденция и сангвиническому темпераменту.

По шкале экстраверсии и интроверсии наглядно видно распределение респондентов первой группы на экстравертов - 66,1\% и интровертов $-33,9 \%$, у второй группы 55,4\% и 44,4\%, у третей - 53,5\% и 46,5\%, у четвертой группы - 56,2 \% и 43,8\% соответственно.

Эмоциональная устойчивость наблюдается у представителей второй, третей и четвертой групп крови. Изучение процентного соотношения показателя устойчивости выявило, что доля эмоционально устойчивых и эмоционально неустойчивых у всех групп отличается. Эмоционально неустойчивыми являются представители первой группы крови. Эмоциональная устойчивость характеризуется способностью сдерживать эмоции, сохранять спокойствие и спокойно реагировать на неблагоприятные обстоятельства. Эмоциональная неустойчивость выражается в чрезвычайной нервности, плохой адаптации, склонности к быстрой смене настроений.

По уровню самооценки среди всех опрошенных лиц с I, II, III группами крови можно выделить средний (нормативный) уровень самооценки - 45,7\%, 45,7\% и 60,5\% соответственно. На выработку такой самооценки влияют мысли, структура восприятия, оценка окружающих, успехи на работе или в школе. Средние показатели самооценки во всех группах испытуемых указывают на средний уровень самооценки, т.е. это нормативный уровень реалистической оценки своих возможностей. При этом нужно отметить, что средние показатели самооценки носителей четвертой группы крови близки к показателям завышенной самооценки.

Изучение процентного соотношения испытуемых с различным уровнем агрессивности показало, что среди носителей первой группы крови по 19,5\% испытуемых излишне агрессивны, $23,7 \%$ чрезмерно миролюбивы, и чуть более половины - умеренно агрессивны $(56,8 \%)$. У носителей второй группы крови излишняя агрессивность наблюдается лишь у 3,0\% испытуемых, умеренная агрессивность выявлена у 66,0\%, и чрезмерная миролюбивость характерна для $31,0 \%$ носителей второй группы крови. Среди представителей третей группы крови умеренно агрессивны $77,2 \%$, излишне агрессивны $10,5 \%$ и чрезмерно миролюбивы $12,3 \%$ испытуемых. У лиц с четвертой группой крови умеренная агрессивность выявлено у $81,3 \%$ опрошенных, чрезмерная миролюбивость - у $18,7 \%$, излишняя агрессивность не выявлена. В целом, независимо от групповой принадлежности, подавляющему большинству испытуемых характерна умеренная агрессивность.

Проанализировав результаты исследования, можно констатировать, что выдвинутая нами гипотеза исследования, подтвердилась. Действительно, существует зависимость особенностей индивидуальности людей от группы крови человека. Для 
более точного определения данной зависимости в будущем нужно будет увеличить количество испытуемых.

$$
* * *
$$

1. Гарбузов В. И. Практическая психотерапия, или как вернуть ребенку и подростку уверенность в себе, истинное достоинство и здоровье. Санкт-Петербург. АО «Сфера», 1994. - 153с.

2. Ильин Е.П. Дифференциальная психофизиология - СПб.: Питер, 2001. - 105-142c.

3. Райгородский Д. Я. Практическая психодиагностика. Учебное пособие.- Самара, 2001. - 52c.

4. Ротманова Н.В. Особенности интегральной индивидуальности человека в связи с различными группами крови / Ротманова Н.В. - Пермь.: ПГПУ, - 2004. - 297с.

5. Фетискин Н.П., Козлов В.В., Мануйлов Г.М. Социально-психологическая диагностика развития личности и малых групп. - М. Изд-во Института Психотерапии. 2002. - 34-86с.

\section{Филина Н.О., Егорова Д.А. Морфогенез Phlox paniculata L. в культуре in vitro} ФГБУН Главный ботанический сад им. Н.В. Цицина РАН (Россия, Москва)

doi: $10.18411 / \mathrm{j}-05-2021-33$

\section{Аннотация}

Работа посвящена усовершенствованию методики культивирования in vitro различных сортов флокса метельчатого. Флокс - ценная декоративная культура. Изучено влияние минерального состава питательной среды на регенерацию микропобегов на стадии микроразмножения. Наиболее высокие значения морфометрических показателей были достигнуты при культивировании на питательной среде MS с добавлением 0,8 мг/л БАП.

Ключевые слова: Phlox paniculata, клональное микроразмножение, коэффициент размножения

\section{Abstract}

The work is devoted to the improvement of the phlox paniculata various varieties cultivation method in vitro. Phlox is a valuable decorative culture. The mineral composition influence of the nutrient medium on the microshoots regeneration has been studied at the proliferation stage. The highest values of morphometric parameters were achieved on MS nutrient medium supplemented with $0,8 \mathrm{mg} / \mathrm{L}$ BAP.

Keywords: Phlox paniculata, clonal micropropagation, multiplication factor

Phlox paniculata L. относится к роду Phlox L. семейства Polemoniaceae Jussieu. Родиной флоксов считают Северную Америку, большинство видов происходит из восточных штатов США. В диком виде флокс метельчатый - типичное равнинное растение и произрастает во влажных светлых лесах, в кустарниках речных долин [1]. Флокс метельчатый и его гибриды по разнообразию окрасок, тонкости рисунка цветков, пышности соцветий, приятному аромату, длительности цветения являются высоко декоративными растениями [2].

Наиболее распространённым методом размножения флоксов является вегетативный (стеблевыми черенками, делением куста, листовыми черенками или пазушными почками с листьями) [3]. Недостатками традиционного вегетативного размножения являются зависимость от сезона, медленная скорость размножения и низкий коэффициент размножения некоторых сортов [4]. С применением биотехнологических методов размножения можно увеличить производство высококачественного посадочного материала малораспространенных сортов флоксов.

Есть несколько сообщений о размножении флокса метельчатого in vitro. В исследовании Джайна и др. для микроразмножения флокса применяли соматический 